\title{
Planetary waves in the upper stratosphere and lower mesosphere during 2009 Arctic major stratospheric warming
}

\author{
P. Kishore ${ }^{1}$, I. Velicogna ${ }^{1,2}$, M. Venkat Ratnam ${ }^{3}$, J. H. Jiang ${ }^{2}$, and G. N. Madhavi ${ }^{4}$ \\ ${ }^{1}$ Department of Earth System Science, University of California, Irvine, CA, 92697, USA \\ ${ }^{2}$ Jet Propulsion Laboratory, California Institute of Technology, Pasadena, CA, USA \\ ${ }^{3}$ National Atmospheric Research Laboratory, Gadanki, Tirupati, India \\ ${ }^{4}$ Department of Physics, Sri Venkateswara University, Tirupati, India
}

Correspondence to: P. Kishore (kishore@uci.edu)

Received: 14 July 2012 - Revised: 7 September 2012 - Accepted: 12 September 2012 - Published: 10 October 2012

\begin{abstract}
The AURA-MLS daily mean temperatures and zonal wind from NASA-MERRA reanalysis for latitudes between $60^{\circ} \mathrm{N}$ and $80^{\circ} \mathrm{N}$ are used to investigate the planetary wave (PW) characteristics in the stratosphere and lower mesosphere during sudden stratospheric warming (SSW) (November 2008 to March 2009). Here, we used a novel method called empirical mode decomposition (EMD) to extract the PWs from the temperature data. The EMD is an interesting approach to decompose signals into locally periodic components, the intrinsic mode functions (IMFs), and will easily identify the embedded structures, even those with small amplitudes. The spectral analysis reveals prevailing planetary wave periods of $\sim 6$-day, $\sim 8$-day, $\sim 15$-day, and $\sim 21$-23-day in IMFs $1,2,3$, and 4, respectively. Clear upward propagation of these waves (20-30 days) is observed, suggesting that sources for these oscillations are in the troposphere.
\end{abstract}

Keywords. Meteorology and atmospheric dynamics (Middle atmosphere dynamics)

\section{Introduction}

The Northern Hemisphere (NH) winter stratosphere is characterized by the occurrence of midwinter sudden warmings (e.g., Labitzke, 1977, 1982). It involves considerable changes of the background wind, temperature, planetary and gravity wave activity and redistributes ozone and other chemicals in high latitudes (Scherhag, 1960). Internal processes or possibly climate change effects could drive the occurrence of such type of winters. The key mechanism behind the sudden stratospheric warming (SSW), initially proposed by Matsuno (1971) and now widely accepted, relates to the growth of upward propagating transient planetary waves (PWs) and their non-linear interaction with the zonal mean flow. Later, SSWs are reasonably well characterized from observational data sets (Labitzke and Naujokat, 2000; Hoffmann et al., 2002, 2007; Venkat Ratnam et al., 2004; Cho et al., 2004; Pancheva et al., 2008) and also through modeling (Newman and Nash, 2004; Manney et al., 2008b).

In connection with SSWs, several studies have shown a weakening and/or reversal of the dominating eastward directed zonal winds in the mesosphere and lower thermosphere region (Manson and Meek, 1991; Singer et al., 1992; Jacobi et al., 2003; Dowdy et al., 2004). The PWs are largescale perturbations of the atmospheric dynamical structure that extends coherently around a full longitude circle. These PWs are a dominant part of the spatial and temporal variability in the stratosphere, and make significant contributions at higher latitudes in the mesosphere (Smith, 2003; Pancheva et al., 2007). Recently, the NH stratospheric winter of 2009 was the most unusual winter, strongest and most prolonged on record (Manney et al., 2009; Thurairajah et al., 2010; Coy et al., 2011). During this event, the stratospheric vortex split and had a more profound impact on the lower stratosphere than previously recorded SSWs. In general, during the SSW event, stronger orographic and thermal forcing in the NH leads to larger PW amplitudes and stronger wave mean flow interactions (Andrews et al., 1987). PWs propagating up from the troposphere can be focused into the stratosphere, causing rapid mean flow changes due to rectified nonlinear effects resulting in warming events (Matsuno, 
1971; Andrews et al., 1987). Charlton and Polvani (2007) reported that during vortex splitting events the wind reversals are longer, stronger, and extend deeper into the lower atmosphere. In the present paper we report the PWs of 330 days, which are present in the AURA_MLS temperature, and NASA-MERRA reanalysis zonal wind data during November 2008 to March 2009 (winter 2009). These PWs are extracted using a relatively new and promising Empirical Mode Decomposition (EMD) technique.

\section{Database and analysis procedure}

\subsection{AURA MLS (MLS)}

The Microwave Limb Sounder (MLS) is one of the four instruments aboard NASA's EOS of the Aura satellite. It looks forward from the Aura spacecraft and scans the Earth's limb vertically from the ground to $\sim 90 \mathrm{~km}$ every $24.7 \mathrm{~s}$. The vertical scan rate varies with altitude, with a slower scan providing greater integration time in the lower regions $(\sim 0-25 \mathrm{~km})$. The Aura satellite is sun-synchronized and is placed in a near polar orbit at $\sim 705 \mathrm{~km}$. The satellite has a radiometer that retrieves temperature from the bands near the $\mathrm{O}_{2}$ spectral line at 118 and $239 \mathrm{GHz}$. The details of the EOS MLS can be found in Waters et al. (2006), Froidevaux et al. (2006) and Schwartz et al. (2008). The temperature precision is typically $\sim 1 \mathrm{~K}$ at the stratospheric altitudes (Schwartz et al., 2008). MLS satellite measures $\sim 3500$ vertical profiles per day along the suborbital track. The effective horizontal resolution of these MLS data is about $200 \mathrm{~km}$ (Schwartz et al., 2006). In this study, we chose MLS version 3.3, level-2 in winter 2009 and each profile up to $\sim 90 \mathrm{~km}$ along the orbit tracks, to 82 degree in each hemisphere.

\subsection{NASA-MERRA (MERRA)}

Required background wind information is taken from the NASA's Global model Assimilation Office (GMAO) atmospheric global reanalysis project: Modern Era RetrospectiveAnalysis for Research and Applications (MERRA). This reanalysis is a 3D-Var assimilation system, the Grid-point Statistical Interpolation (GSI) scheme, and a variational bias correction of satellite radiances (Rienecker et al., 2008; Kleist et al., 2009). The assimilation system utilizes the Goddard Earth Observing System model, Version 5 (GEOS-5; Rienecker et al., 2011). The MERRA analysis, covering 1979 through the present, is produced over the period of observations where satellite observations are most reliable, with an objective to improve upon the representation of the global temperature and water cycle in the reanalysis. The MERRA data set has horizontal resolution of $2 / 3$ longitude $\times 1 / 2$ latitude with 42 vertical levels available at 6 -h intervals. The vertical resolution is $1 \mathrm{~km}$ starting at the $10 \mathrm{~km}$ altitude level and increasing to $\sim 2 \mathrm{~km}$ at the $60 \mathrm{~km}$ altitude level.
As mentioned earlier, mean flow and upward propagation planetary wave interactions seem to play a key role in the initiation and progression of major SSWs (Matsuno, 1971). Such an event can strongly affect the entire middle atmosphere, causing variations in the stratosphere. It is well known that the time period preceding the onset of the SSW is usually characterized by more than one type of PW present concurrently in the stratosphere. It is shown that the observed zonally symmetric PWs are related to this major SSW in winter 2009. Therefore, we need to investigate which types of waves are observed during the SSW period. In order to examine the most prominent PW characteristics in the stratosphere and lower mesosphere during the SSW event, we use MLS temperature during winter 2009.

\subsection{Empirical mode decomposition (EMD)}

To investigate the PWs in the upper stratosphere and lower mesosphere, a relatively new and promising EMD technique has been performed on the temperature and zonal winds. The EMD is a highly adaptive decomposition technique first introduced by Huang et al. $(1998,1999,2008)$. It decomposes any complicated signal into so-called intrinsic mode functions (IMFs), and leads to a clean representation of the signal by a few well behaved signal components. In addition, this method is empirical because the local characteristic time scales of the data themselves are used to decompose the time series. The number of modes and frequencies of each mode are inherently determined by these time scales (Coughlin and Tung, 2004; Huang et al., 2012). This adaptive technique is derived from the simple assumption that any signal consisting of different IMFs should satisfy two conditions: (1) in the whole data set, the number of extrema and number of zero crossings are either equal or differ at most by one. (2) At any point, the mean value of the envelope defined by local maxima and the envelope defined by the local minima approach is zero (Huang et al., 1998). We construct upper and lower envelopes by connecting all maxima or all minima with cubic splines and subtract the mean of the upper and lower envelopes from the original signal to get a component, and these two characteristics are also the criteria for shifting processes and stopping (Deng et al., 2009). The modes of oscillation are the components that retain the features of natural oscillations in the overall signal, independent of each other. By integrating all the IMFs and the residue, the original signal is recovered. Deng et al. (2009) successfully detected the small targets under complicated sea-sky backgrounds using EMD method, and this method can decompose signal selfadaptively and efficiently. The performance and limitations of the EMD are discussed by Datig and Schlurmann (2004). A more detailed discussion of IMF method, i.e., about local maxima, local minima, envelopes and graphical representation of the IMF, are discussed in the later section. 


\section{Results}

Figure 1a shows the time series of daily zonal mean temperature anomaly observed at various altitudes $(32 \mathrm{~km}, 42 \mathrm{~km}$, $52 \mathrm{~km}$, and $62 \mathrm{~km}$ ) representing the stratosphere and lower mesosphere derived from MLS temperature over the latitude range of $60-80^{\circ} \mathrm{N}$ during winter 2009 . In addition, daily zonal mean wind from MERRA reanalysis data set at $32 \mathrm{~km}$ $(10 \mathrm{hPa})$ over $60^{\circ} \mathrm{N}$ is shown in Fig. 1a. From Fig. 1a, the onset of the major SSW is at day 24 (24 January 2009) and it is defined by the zonal mean zonal wind reversal at $10 \mathrm{hPa}$ over $60^{\circ} \mathrm{N}$ latitude. These results are consistent with that reported by Manney et al. (2009) that during the 2008-2009 winter, a major warming occurred with reversal of zonal wind and temperature gradient on 24 January 2009.

The temperature anomaly at $32 \mathrm{~km}$ and $42 \mathrm{~km}$ altitudes in Fig. 1a shows gradual increase in the mid of January 2009 and it reaches maximum of $\sim 40 \mathrm{~K}$ at 23 January 2009 , followed by an equally sharp fall in late January, and does not recover to its typical levels until mid February. A sharp peak in mid-January 2009 to highly anomalous values is noticed in the mid-stratosphere, and a subsequent rapid drop in $60^{\circ} \mathrm{N}$ zonal mean wind is observed, as also reported by Manney et al. (2009). Thus, the major warming can be clearly identified in the MLS temperature anomalies at the stratospheric altitudes $(32 \mathrm{~km}$ and $42 \mathrm{~km})$, and temperature increases of about $\sim 40 \mathrm{~K}$ are observed. Similarly, Kurihara et al. (2010) using NCEP reanalysis data showed a rapid increase of zonal temperature of about $50 \mathrm{~K}$ at $10 \mathrm{hPa}$ pressure level over $70^{\circ} \mathrm{N}$. Such a strong temperature variability during SSWs is traditionally linked to the presence of PWs and their interactions with the circumpolar flow (e.g., Matsuno, 1971; Andrews et al., 1987).

Figure $1 \mathrm{~b}$ shows the latitudinal variability of the temperature perturbations at $32 \mathrm{~km}$. Strong enhancement in the temperature perturbations are observed between days 20 and 45 in all the latitudinal bands. The maximum temperature anomaly is observed on 23 January 2009 in three latitude bands $\left(60^{\circ} \mathrm{N}, 70^{\circ} \mathrm{N}\right.$, and $\left.80^{\circ} \mathrm{N}\right)$. Stronger positive temperature anomaly exists at high latitudes and decreases, moving towards mid-latitudes. A slight delay in the enhancement is also observed with respect to latitude, with first enhancing at polar latitudes. This indicates that the major SSW in winter 2009 has spread out into the middle-high latitudes.

The upper stratosphere and lower mesospheric daily zonal mean temperature observed by the MLS, its anomalies, daily zonal mean zonal wind observed by the MERRA, and zonal wind anomalies over the latitude range $60-80^{\circ} \mathrm{N}$, centered at $70^{\circ} \mathrm{N}$ as a function of time and height, are shown in Fig. 2. The temperature and zonal wind anomalies are calculated at each altitude level by removing the daily zonal means from the winter climatology over the periods from November 2008 to March 2009. The vertically varying temporal evolution of the composite SSW can be seen clearly from Fig. 2 . The altitude range between 20 and $70 \mathrm{~km}$ height is investigated. The
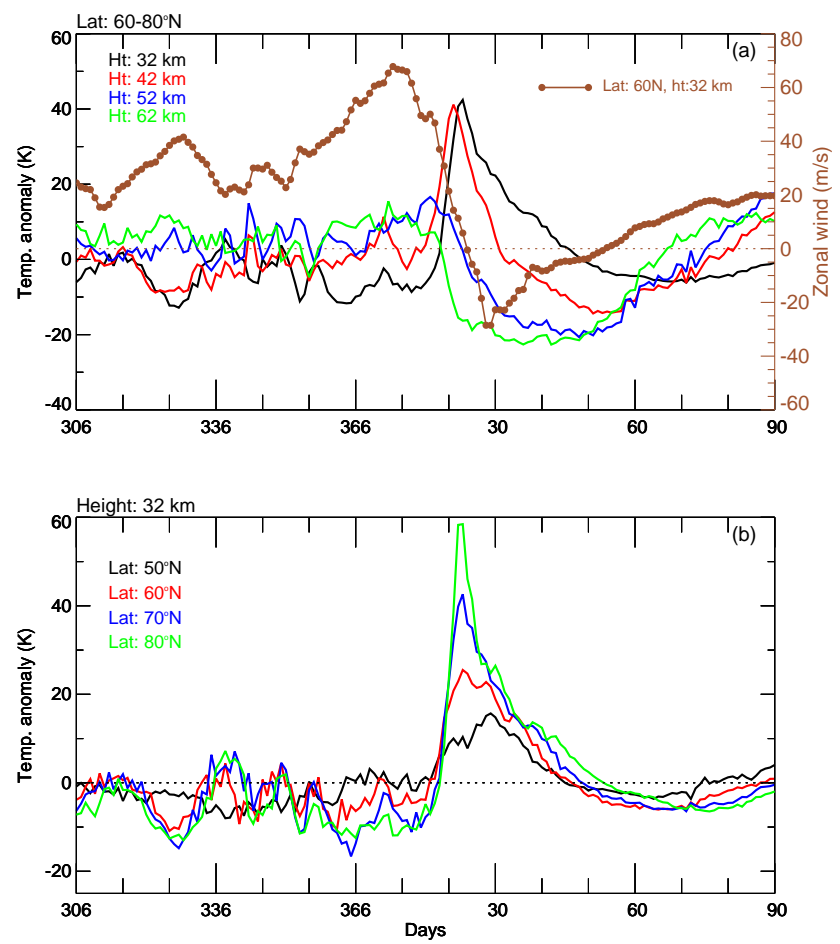

Fig. 1. (a) Daily MLS temperature anomalies at 32, 42, 52, and $62 \mathrm{~km}$ altitude levels averaged for latitude range $60-80^{\circ} \mathrm{N}$ observed during November 2008 to March 2009. Zonal mean zonal wind from MERRA reanalysis over $60^{\circ} \mathrm{N}$ at $32 \mathrm{~km}$ altitude level is also shown. (b) The latitudinal variability of the temperature anomaly at $32 \mathrm{~km}$ altitude level for the latitudes $50-80^{\circ} \mathrm{N}$ is shown.

daily mean temperature shows maximum near stratopause region (between 50 and $60 \mathrm{~km}$ ). The stratopause temperature is around $255 \mathrm{~K}$ in January 2009 , and it slowly increases to $275 \mathrm{~K}$ by 20 January 2009 . The warm layer plunges from $55 \mathrm{~km}$ to $30 \mathrm{~km}$ and it extends up to $20 \mathrm{~km}$. The maximum warm temperature is observed on 23 January between the 30 to $50 \mathrm{~km}$ altitude region. Quiroz (1971) suggested the stratospheric warming start in the upper stratosphere and move down to the lower levels. The zonal wind reversal at $65 \mathrm{~km}$ occurred on 21 January, 3 days earlier than at the $32 \mathrm{~km}$ $(10 \mathrm{hPa})$, and clearly propagated downward at the rate of about $12 \mathrm{~km}$ per day. Earlier it was shown that the zonal mean zonal wind reversal below $90 \mathrm{~km}$ that occurs around the same time also propagates down to the stratosphere (Manney et al., 2009). Beginning in January, the zonal wind was westerly between 30 and $65 \mathrm{~km}$ altitude and peaked around mid-January, reaching a maximum of $65-70 \mathrm{~m} \mathrm{~s}^{-1}$, and then reversed to easterly on 24 January 2009 . The easterly winds were strong at about $30-40 \mathrm{~m} \mathrm{~s}^{-1}$ between 30 and $60 \mathrm{~km}$ altitudes. There is very good correlation between the warm temperatures observed by MLS and zonal winds taken from MERRA during this period. This behavior is consistent with that described in other studies (e.g., Manney et al., 2008a, 2009; Coy et al., 2011) as a manifestation of a major SSW (defined as 

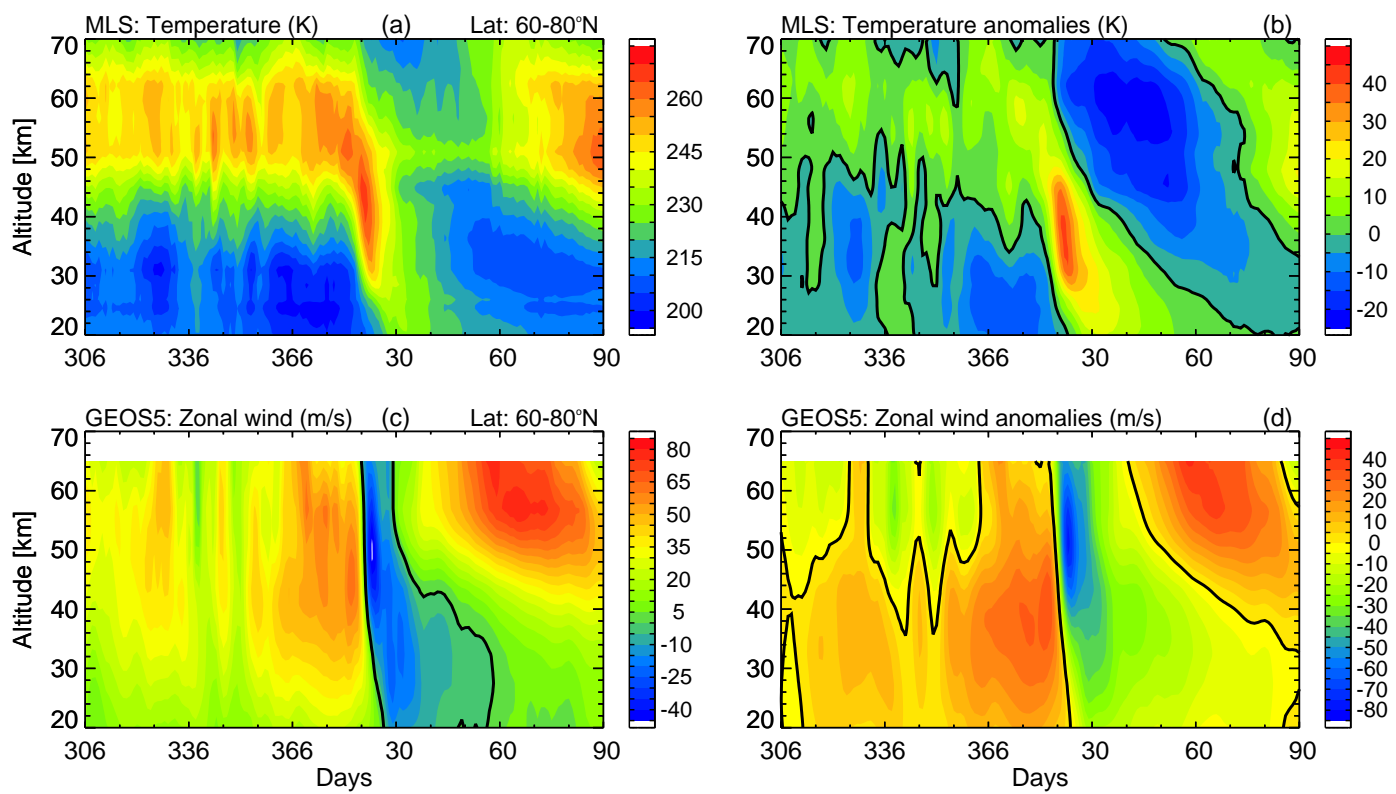

Fig. 2. Time-altitude sections of the (a) MLS temperature, (b) temperature anomalies, (c) zonal mean zonal wind from MERRA reanalysis, and (d) zonal wind anomalies centered over latitude range $60-80^{\circ} \mathrm{N}$ during November 2008 to March 2009. A thick solid black line represents the zero wind.

having easterly winds down to $10 \mathrm{hPa}$ at $60^{\circ} \mathrm{N}$ ) during last week of January 2009. A large temperature anomaly with reversed temperature gradient is observed (Fig. 2b) at days 10 (10 November 2008), 33 (1 December 2008), and 50 (mid of December 2008). Another strong temperature gradient occurred on 23 January 2009, lasting four weeks at $32 \mathrm{~km}$ altitude level. This disturbance was accompanied by rapid deceleration of the zonal mean wind anomaly (Fig. 2d), and other three pulses wind reversals reached only up to $40 \mathrm{~km}$. The reversal wind (west ward) at $32 \mathrm{~km}(\sim 10 \mathrm{hPa}$ pressure level) continued up to day 150 . The observed latitudinal dependence of the wind reversal of eastward-directed winds with reduced magnitudes towards the Equator was more pronounced during SSW in 1998/99 (Hoffmann et al., 2002).

The IMFs of the MLS temperature anomaly data are shown in Fig. 3. Starting from the top of each figure, the original temperature anomaly $\left(P_{\mathrm{o}}(t)\right)$ data, the IMF components $(1,4$, and 6$)$ are plotted. For getting anomaly daily temperature data during period November 2008 to March 2009, between $60^{\circ} \mathrm{N}$ and $80^{\circ} \mathrm{N}$ are averaged. These averaged values are subtracted from every day's temperature data at each altitude level. The method of extraction of IMFs is briefly described below. We first identify all the points of the local maxima and local minima in the time series of the data set. These are marked using blue and red dots, respectively, in Fig. 3. We then create a positive $(\mathrm{E}+)$ envelope by spline interpolation of the local maxima and the negative envelope (E-) by spline interpolation of the local minima of the input data set, shown as blue and red curves in Fig. 3. For this analysis we used cubic spline interpolation, as suggested by
Huang et al. (1998). For each time instant, we compute the mean $\left(m_{\mathrm{o}}(t)\right)$ value using positive and negative envelopes. The signal mean $\left(m_{0}(t)\right)$ is referred to as the envelope mean and is in Fig. 3 with black bold line. This mean value is subtracted from the data series to get $P_{1}(t)=P_{\mathrm{o}}(t)-m_{\mathrm{o}}(t)$. The new time series $\left(P_{1}\right)$ is shown in Fig. 3 as mentioned as a 1 st iteration. The new time series is further processed as in the previous step to get $P_{2}(t)=P_{1}(t)-m_{1}(t)$. This process is repeated $\mathrm{m}$ times once the mean of the envelope is close enough to zero. Such an $P_{\mathrm{m}}(t)$ is the first intrinsic mode function denoted as $\mathrm{IMF}_{1}$. Originally Huang et al. (1998, their Eq. 5.5) repeated these steps until integral condition was satisfied. In later papers they adopted stopping criterion based on the number extrema and zero crossings. After the first IMF is found and subtracted from the original time series $\left(P_{\mathrm{o}}(t)\right)$, the procedure is repeated to find the second IMF. These steps are iterated until only a linear trend remains.

For the time series shown in Fig. 3, eight IMFs can be extracted. In Fig. 4 for clarity we show the first four IMFs of the data in the order they are extracted. It can be easily observed that all IMFs exhibit slow varying amplitudes and frequencies. In order to investigate the gross characteristics of oscillations with dominant periods, we applied Lomb Scargle (L-S) periodogram analysis to the temperature data; each IMF and resultant amplitude spectral plots are plotted at right side of the Fig. 4. Compared to the other methods, the L-S method weights the data on a per point basis instead of a per time interval basis (Press et al., 1992). It scores over conventional Fourier techniques because of its ability to deal directly with time series having missing data, and its 


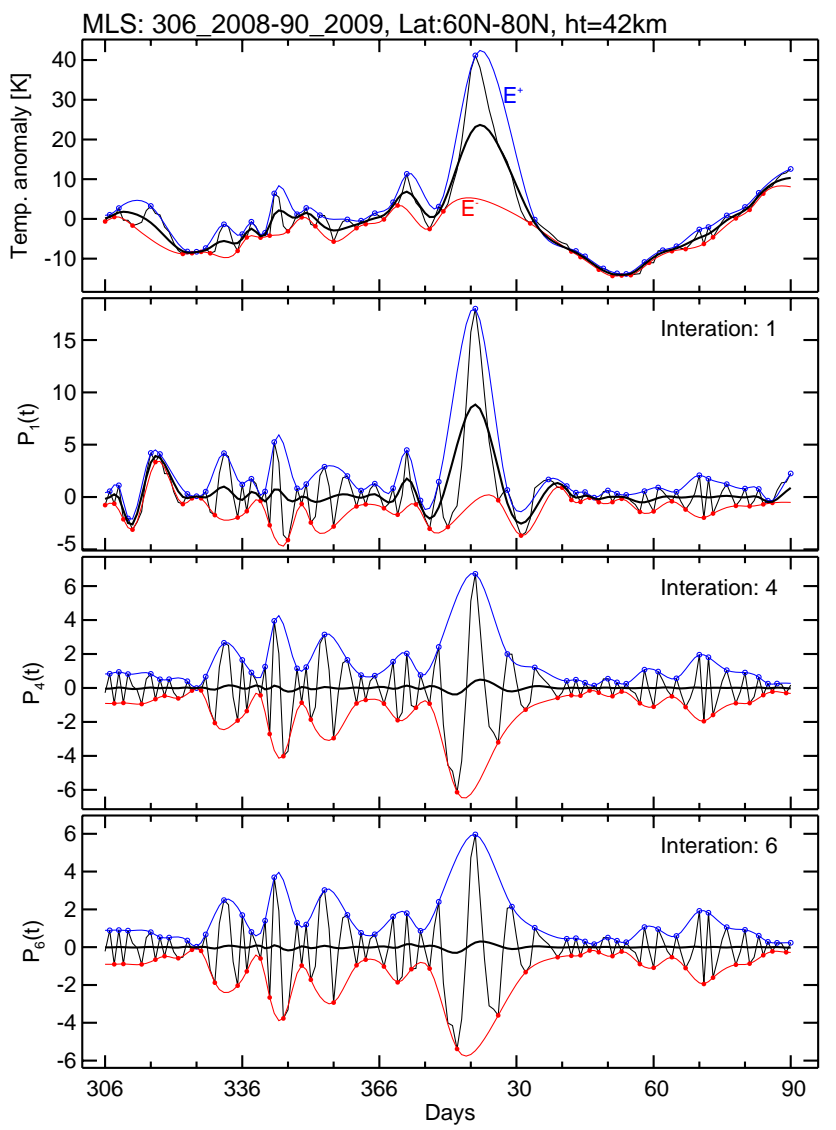

Fig. 3. Procedure showing the extraction of first intrinsic mode function (IMF) from MLS temperature anomaly over latitude 60$80^{\circ} \mathrm{N}$ at $42 \mathrm{~km}$ altitude level during November 2008 to March 2009. See text for details.

straightforward significance level regime (Fraser et al., 1993; Lawrence et al., 1995). Figure 4 displays the dominant oscillations in the MLS temperatures over latitude range 60$80^{\circ} \mathrm{N}$ at altitude $42 \mathrm{~km}$ during winter 2009 , and the $95 \%$ confidence level is indicated with a dashed line. From the L-S spectral plot four dominant periods are observed during the SSW. The first IMF contains a 3.6-day period as most dominant. The second IMF has broad periods with an average period of 6-8 days. Third IMF dominates with maximum amplitudes at $\sim 14$ day and $\sim 17$ day periods, and the fourth IMF shows clearly longer periods, i.e., 20-32 day periods. Recently Mbatha et al. (2010) observed the PW periods less than 15 days (14-, 10-, and 5-day) during the SSW using SANAE HF radar data sets. All these oscillations are not shown in the original time series of data set (see top of Fig. 4); and shows only 20-25 periods of oscillations during the SSW. Similarly, analysis performed on the MERRA zonal wind data over $60^{\circ} \mathrm{N}$ and $80^{\circ} \mathrm{N}$ at $42 \mathrm{~km}$ altitude level showed the oscillations with 3.6-day, 9-11 day, 17-25 day, and 25-32 day periods (figure not shown). When we compared the winter 2009 SSW spectra to the other normal years (figure not shown), we noticed that other years do not have strong presence of the above mentioned PWs. All these propagating waves have large amplitudes. It is worth mentioning here that the decomposed oscillations are only a small part of the whole PW spectrum. Similarly, Pancheva et al. (2007) found three prevailing periods of $\sim 23,17$ and 11 days with large amplitudes in the zonal wind data of the $\mathrm{NH}$ stratospheric altitudes centered at $50-60^{\circ} \mathrm{N}$ in the winter 2003 2004 using UK Met Office data sets.

Note that the dominant periods of the PWs observed during the winter 2009 are provided above; however, it was not clear exactly when these periods dominate. To provide the time description of the PW periods as a function of dominant periods and time, wavelet analysis was performed on the MLS temperature and IMFs, as shown in Fig. 4, and the resultant amplitudes are shown as contours in Fig. 5. The wavelet transform is localized transform (relative to the overall transform of a given time-sequence used by the Fourier transform) in both time and frequency (Kumar and FoufoulaGeorgiou, 1997). Figure 5 shows the wavelet amplitude spectra calculated at $32 \mathrm{~km}$ and $42 \mathrm{~km}$ over the latitude range $60-80^{\circ} \mathrm{N}$ during the winter 2009 for the temperature and first four IMFs. The $95 \%$ confidence level is indicated with black line. The analysis covers the wave periods between 3 to 30 days. When the wavelet is applied to the original MLS temperature anomaly data, it shows clearly the dominant periods greater than 15 days, which maximizes near days 60 100 , and does not show any wave periods less than 15 days at both altitude levels.

We further applied the wavelet analysis for the first four IMFs at $32 \mathrm{~km}$ and $42 \mathrm{~km}$ altitude levels. Four dominant wave periods during winter 2009 SSW are observed. The first IMF shows the presence of 4-8-day wave, and its maximum amplitude at $\sim 6$ day on around day 50 (20 December 2008). In the second IMF, the waves with peak between 6-10 days, and the peak amplitude at $\sim 8$-day centered at day 85 (24 January 2009), are observed. In the third IMF, a clear peak between 13-18 days, and the maximum peak at around $\sim 15$-day on day number 80 (19 January 2009), is noticed. The fourth IMF period covers 17-24 day periods and extends nearly two months during the observational period, where its maximum amplitudes are observed one month before and after the SSW event. The PWs with short periods, e.g., quasi-two-day wave characterized by bursts of activity, vary on scales of several days (Pancheva, 2006; Malinga and Ruohooniemi, 2007). At $42 \mathrm{~km}$ altitude level, the maximum peaks at around $\sim 3.6$ day, $\sim 8$ day, $\sim 15$ day, and $\sim 21-23$ day are observed during the winter 2009 for the four IMFs, respectively. These are in agreement with the work of Pancheva et al. (2008), the dominating wave periods of $\sim 22$ $23, \sim 16$ day and $\sim 11$ day in the stratospheric heights using UKMO zonal wind during 2003-2004 winter period. This clearly indicates that the PW periods varied from 3-30 days during the winter 2009 at stratospheric altitude levels. From the figure, it is clear that temperatures on 13-25 day, together 

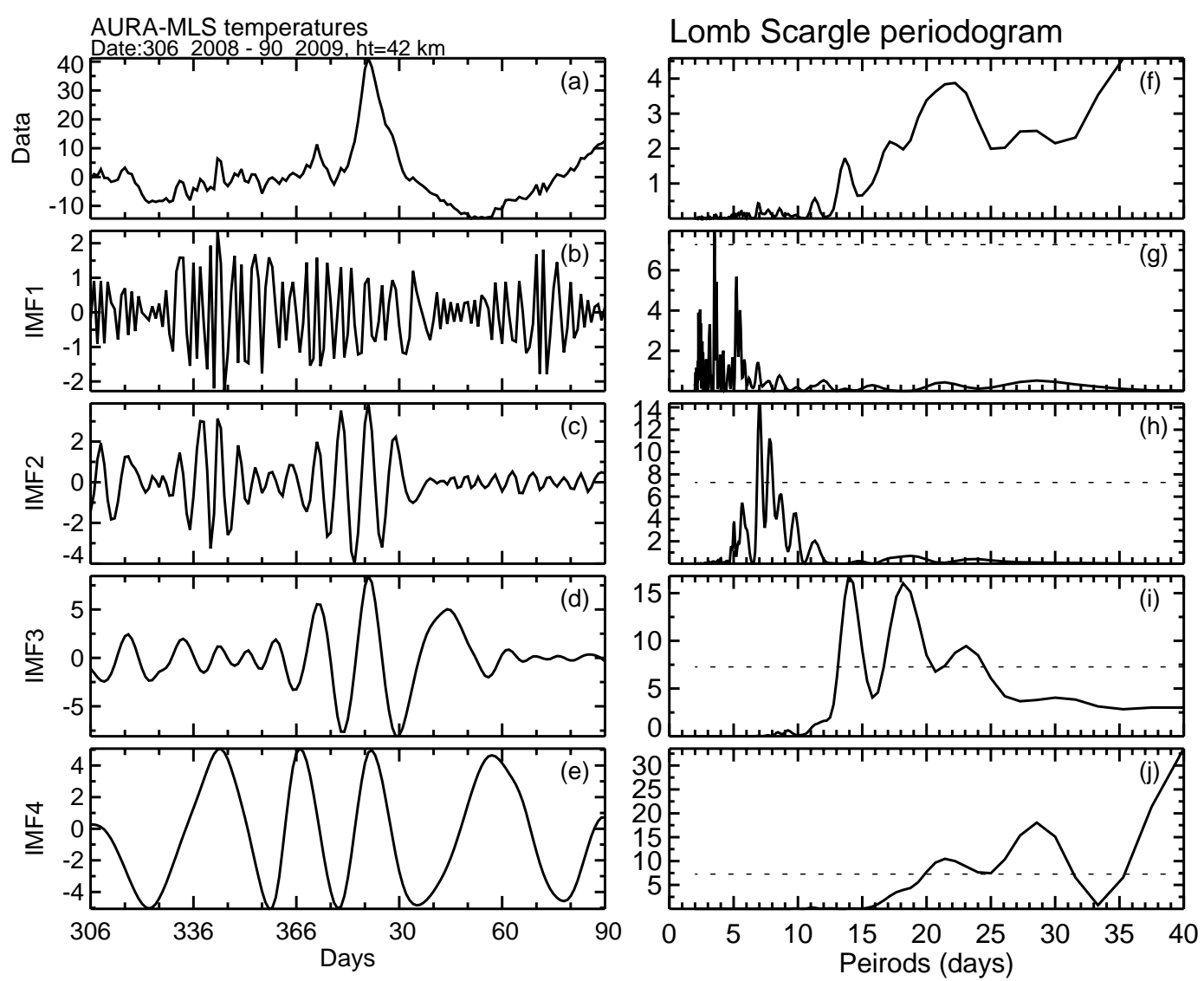

Fig. 4. Time series of (a) daily mean temperature anomalies observed using MLS during November 2008 to March 2009 at $42 \mathrm{~km}$ altitude level. Intrinsic mode function components from the first to fourth IMFs are shown in (b) to (e). Corresponding L-S periodograms are shown in (f) to (j), respectively. Dashed horizontal line in (g) to (j) indicates $95 \%$ confidence level.

Table 1. Planetary wave periods observed four different heights $(32,42,52$ and $62 \mathrm{~km})$ using MLS temperature and MERRA reanalysis zonal winds over the latitude range of $60-80^{\circ} \mathrm{N}$ during 2009 stratospheric warming period.

\begin{tabular}{|c|c|c|c|c|c|}
\hline \multicolumn{6}{|c|}{ Planetary wave periods: MLS temperature $\left(60^{\circ} \mathrm{N}-80^{\circ} \mathrm{N}\right)$} \\
\hline Height $(\mathrm{km})$ & Data & IMF1 & IMF2 & IMF3 & IMF4 \\
\hline 32.0 & $>15$ days & $4-8$ days ( $\sim 6$ day) & $6-10$ days ( $\sim 8$ day) & 13-18 days $(\sim 15$ day $)$ & 17-24 days ( $\sim 18$ day) \\
\hline 42.0 & $>16$ days & $3-6$ days ( $\sim 4$ day) & $6-10$ days ( $\sim 8$ day) & 13-22 days ( $\sim 15$ day) & $18-28$ days ( $~ 22$ day) \\
\hline 52.0 & $>25$ days & 4-7 days ( $\sim 5$ day) & $7-11$ days ( $\sim 8$ day) & $10-25$ days ( $\sim 15$ day) & - \\
\hline 62.0 & $>30$ days & 6-10 days ( $\sim 7$ day) & $8-12$ days ( $~ 10$ day) & $10-15$ days ( $\sim 13$ day) & 16-24 days ( $\sim 18$ day) \\
\hline \multicolumn{6}{|c|}{ Planetary wave periods: NASA MERRA Zonal winds $\left(60^{\circ} \mathrm{N}-80^{\circ} \mathrm{N}\right)$} \\
\hline 32.0 & $>15$ days & 4-6 days ( $\sim 5$ day) & 6-11 days ( $\sim 8$ day) & 13-21 days ( $\sim 15$ day) & $14-26$ days ( $\sim 21$ day) \\
\hline 42.0 & $>15$ days & $4-6$ days ( $\sim 5$ day) & $6-10$ days ( $\sim 8$ day) & $12-22$ days ( $\sim 15$ day) & $16-26$ days ( $\sim 21$ day) \\
\hline 52.0 & $>10$ days & $4-8$ days ( $\sim 6$ day) & $7-11$ days ( $\sim 8$ day) & $12-23$ days ( $\sim 15$ day) & $17-26$ days ( $\sim 22$ day) \\
\hline 62.0 & $>20$ days & $4-8$ days ( $\sim 6$ day) & $7-13$ days $(\sim 10$ day $)$ & $12-20$ days ( $\sim 15$ day) & - \\
\hline
\end{tabular}

with waves on 20-30 day, indicate a seasonal pattern characterized by enhanced wave activity in winter superimposed by short-term fluctuations. We did the analysis for different altitudes of MLS temperatures and their dominant periods are tabulated in Table 1 . We estimated the PWs using MLS temperature, and MERRA reanalysis zonal wind for four altitude $(32,42,52$, and $62 \mathrm{~km})$ levels. We observed bursts of wave activity during SSW period and the maximum peak oscillations are shown in the parentheses in Table 1. A very good comparison in the dominant central periods between 

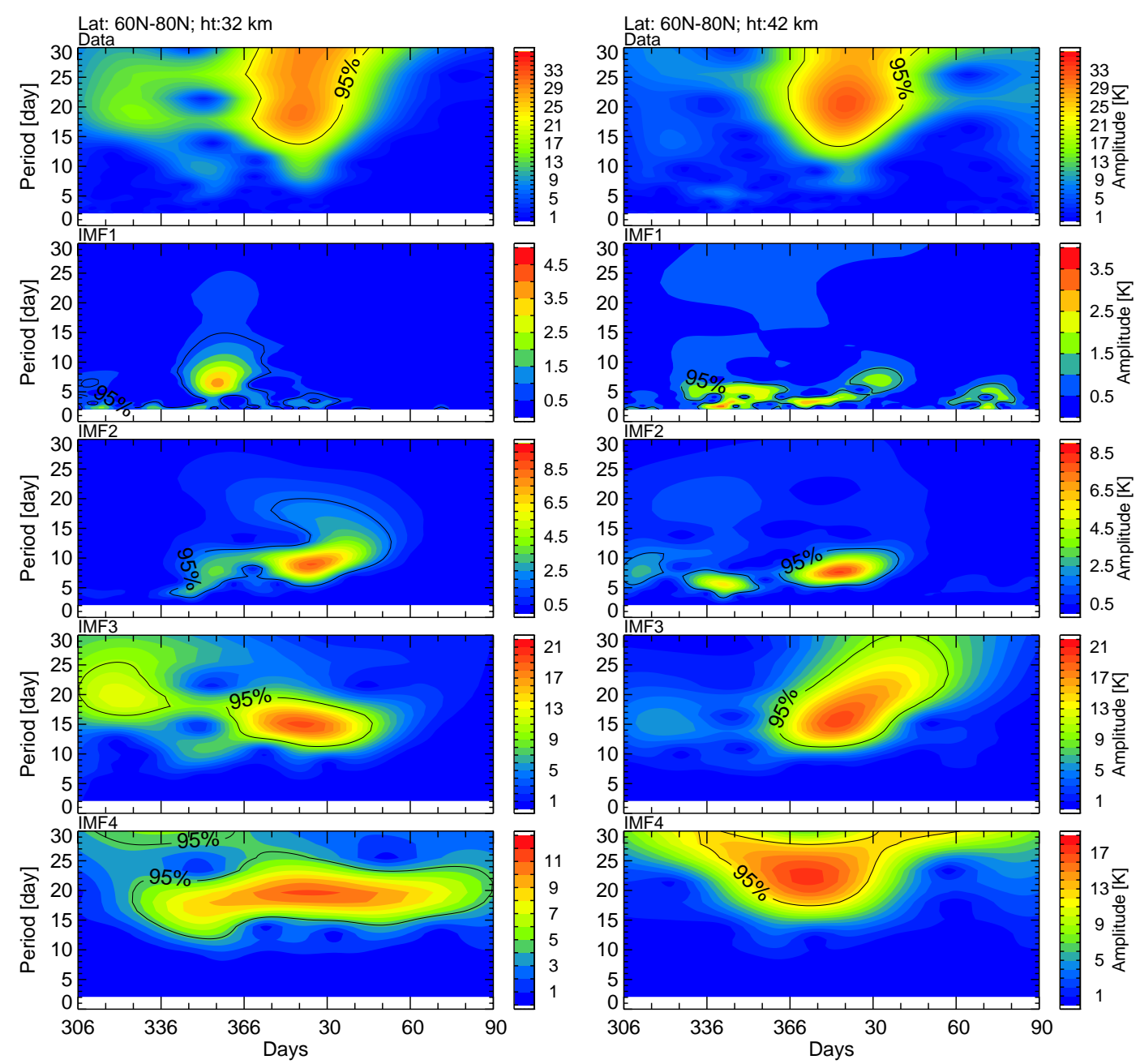

Fig. 5. Contours of wavelet intensities as a function of frequency and time for the temperature anomaly and first four IMFs shown in Fig. 4 over latitude range $60-80^{\circ} \mathrm{N}$ at both $32 \mathrm{~km}$ (left panels) and $42 \mathrm{~km}$ (right panels) altitude levels.

the waves with MLS temperatures and MERRA winds can be observed from the table. During SH winter, Dowdy et al. (2004) observed a distinct change in the character of the planetary-wave field associated with SSW events. This is most likely due to the changes in the filtering by the stratospheric winds brought about by the wind reversal.

In order to investigate the gross characteristics of oscillations with periods 20-30 days, we applied Lomb-Scargle periodogram analysis to the time series of temperature anomaly data sets during the winter 2009 period. Figure 6 shows the amplitude and the corresponding phase in the altitude range of $20-70 \mathrm{~km}$ over the latitude range of $60-80^{\circ} \mathrm{N}$. The analysis covers the wave periods between 20-30 days. In this process, we have estimated the confidence levels of the periodograms and only those spectral peaks with more than a $95 \%$ confidence level are considered. The amplitude is less than $4 \mathrm{~K}$ at $20 \mathrm{~km}$ altitude level, increases and maximizes nearly at $30 \mathrm{~km}$ with amplitude of $\sim 7 \mathrm{~K}$. Above $30 \mathrm{~km}$, its amplitude remains around $\sim 6 \mathrm{~K}$ and extends up to $42 \mathrm{~km}$.
The minimum amplitude of about $2.5 \mathrm{~K}$ is observed at around $50 \mathrm{~km}$ altitude level. A clear downward phase progression indicating upward wave propagation can be noticed. This indicates that the sources for these waves are in the troposphere.

\section{Conclusions}

In the present study, we have investigated the PW activity in the upper stratosphere and lower mesosphere over latitude region $60-80^{\circ} \mathrm{N}$ using MLS temperature and NASA-MERRA zonal wind during the unprecedented major SSW that occurred from November 2008 to March 2009. This SSW is one of the major warmings, which occurred with reversal of zonal wind on 24 January 2009 (Fig. 1a). This SSW is more pronounced in the NH high latitudes, expanding to the middle latitudes $\sim 50^{\circ} \mathrm{N}$ (Fig. 1b). During the SSW, the PWs with periods between 3 and 30 days in both wind and temperatures are observed (Fig. 4) using EMD technique. The 

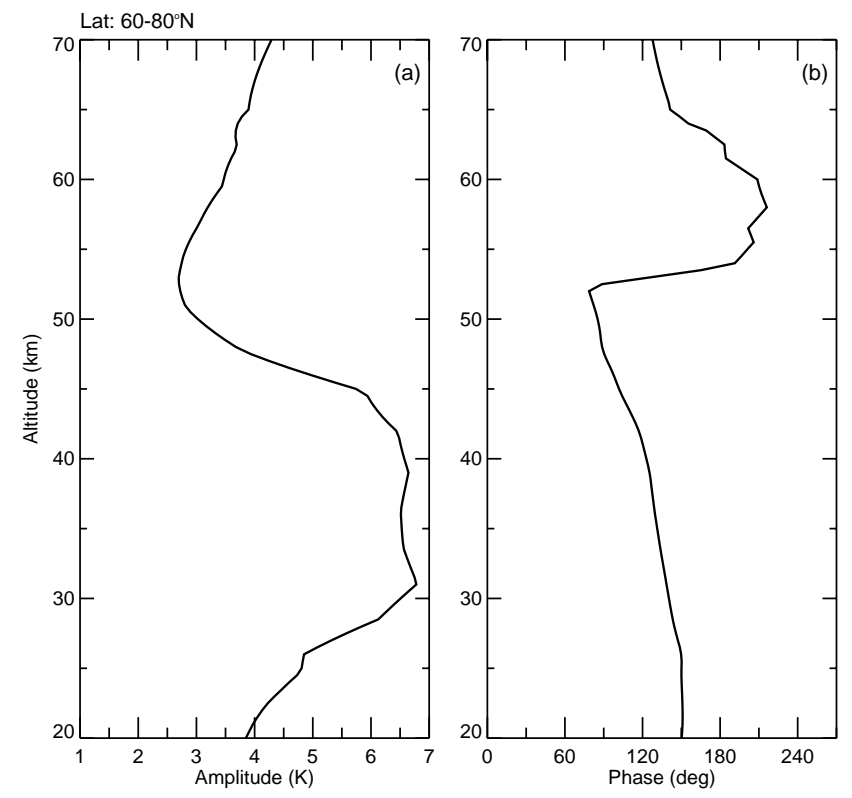

Fig. 6. Profiles of (a) amplitude and (b) phase of 20-30 day waves observed over $60-80^{\circ} \mathrm{N}$ latitude range during November 2008 to March 2009.

EMD method is very effective; it decomposes the time signal and extracts the possible PW periods at each IMF. We applied this method for different altitude levels (32, 42, 52, and $62 \mathrm{~km}$ ) and found PWs with dominant periods of $\sim 4$ 7 days in IMF1, $\sim 8-10$ days in IMF2, and $\sim 13-15$ day periods in IMF3. Similarly, we observed PWs in the MERRA zonal wind, as clearly mentioned in Table 1 .

The PW activity is enhanced in the upper stratosphere and lower mesosphere region. The results show that an upward propagating, 20-30 day planetary wave was present during the SSW period (Fig. 6). In the present paper we have shown that a number of PW features of middle atmosphere are able to be extracted using EMD technique. The EMD signal processing algorithm has been established to perfectly analyze for single dimension array (Huang et al., 1998). Later, Sinclair and Pegram (2005), extended the EMD algorithm into two-dimensional array and its application to radar rainfall data, as well as examining temporal persistence in the data at different spatial scales. This decomposition technique has also been extended to analyze two-dimensional (2-D) data/images, which is known as bi-dimensional EMD (BEMD), 2-D EMD and so on (Damerval et al., 2005; Xu et al., 2006). We emphasize use of such techniques to extract the signals even with the small amplitudes. Further studies extending our analysis to the stratospheric warming and mesospheric cooling events are required in order to generalize these results.

Acknowledgements. The authors would like to thank all the members of AURA_MLS, and NASA_MERRA reanalysis data centers for the public access via their web sites. The co-author J. H. Jiang thanks the support by the Jet Propulsion Laboratory, California Institute of Technology, under contract with NASA. The authors would like to thank editor and the two anonymous reviewers for their critical evaluation of the manuscript.

Topical Editor C. Jacobi thanks two anonymous referees for their help in evaluating this paper.

\section{References}

Andrews, D. G., Holton, J. R., and Leovy, C. B.: Middle Atmospheric Dynamics, Academic Press, 489 pp., 1987.

Charlton, A. J. and Polvani, L. M.: A new look at stratospheric sudden warmings. Part I: Climatology and modeling benchmarks, J. Climate, 20, 449-469, 2007.

Cho, Y. M., Shepherd, G. G., Won, Y. I., Sargoytchev, S., Brown, S., and Solheim, B.: MLT cooling during stratospheric warming events, Geophys. Res. Lett., 31, L10104, doi:10.1029/2004GL019552, 2004.

Coughlin, K. and Tung, K. K.: Eleven-year solar cycle signal throughout the lower atmosphere, J. Geophys. Res., 109, D21105, doi:10.1029/2004JD004873, 2004.

Coy, L., Eckermann, S. D., Hoppel, K. W., and Sassi, F.: Mesospheric precursors to the major stratospheric sudden warming of 2009: Validation and dynamical attribution using a groundto-edge-of-space data assimilation system, J. Adv. Model. Earth Syst., 3, M10002, doi:10.1029/2011MS000067, 2011.

Damerval, C., Meignen, S., and Perrier, V.: A fast algorithm for bidimensional EMD, IEEE Signal Processing Lett., 12, 701-705, 2005.

Datig, M. and Schlurmann T.: Performance and limitations of the Hilbert Huang transformation (HHT) with an application to irregular water waves, Ocean Engg., 31, 1783-1834, 2004.

Deng, H., Liu, J., and Li, H.: EMD based Infrared image target detection methods, Journal Infrared Milli Terahz Waves, 30, 12051215, 2009.

Dowdy, A., Vincent, R. A., Murphy, D. J., Tsutsumi, M., Riggin, D. M., and Jarvis, M. J.: The large scale dynamics of the mesosphere-lower thermosphere during the Southern Hemisphere stratospheric warming of 2002, Geophys. Res. Let., 31, L14102, doi:10.1029/2004GL020282, 2004.

Fraser, G., Hernandez, G., and Smith, R.: Eastward-moving 24 day in the winter Antarctic mesosphere, Geophys. Res. Lett., 20, 1547-1550, 1993.

Froidevaux, L., Livesey, N. J., Read, W. G., Jiang, Y. B., Jimenez, C., Filipiak, M. J., Schwartz, M. J., Santee, M. L., Pumphrey, H. C., Jiang, J. H., Wu, D. L., Manney, G. L., Drouin, B. J., Water, J. W., Fetzer, E. J., Bernath, P. F., Boone, C. D., Walker, K. A., Jucks, K. W., Toon, G. C., Margitan, J. J., Sen, B., Webster, C. R., Christensen, L. E., Elkins, J. W., Atlas, E., Lueb, R. A., and Hendershot, R.: Early validation analyses of atmospheric profiles from EOS MLS on the AURA satellite, IEEE Trans. Geosci. Remote Sens., 44, 1106-1121, 2006.

Hoffmann, P., Singer, W., and Keuer, D.: Variability of the mesospheric wind field at middle and Arctic latitudes in winter and its relation to stratospheric circulation disturbances, J. Atmos. Terr. Phys., 64, 1229-1240, 2002.

Hoffmann, P., Singer, W., Keuer, D., Hocking, W., Kunze, D., and Mutayama, Y.: Latitudinal and longitudinal variability of meso- 
spheric winds and temperatures during stratospheric warming events, J. Atmos. Solar Terr. Phys., 69, 2355-2366, 2007.

Huang, N. E. and Wu, Z.: A review on Hilbert-Huang Tranform: the method and its applications on geophysical studies, Rev. Geophys., 46, RG2006, doi:10.1029/2007RG000228, 2008.

Huang, N. E., Shen, Z., Long, S. R., Wu, M. C., Shih, H. H., Zheng, Q., Yen, N.-C., Tung, C. C., and Liu, H. H.: The empirical mode decomposition and the Hilbert spectrum for nonlinear and nonstationary time series analysis, Proc. R. Soc. Lond., A 454, 903995, 1998

Huang, N. E., Shen, Z., and Long, S. R.: A new view of nonlinear water waves: the Hilbert spectrum, Annu. Rev. Fluid Mech., 31, 417-457, 1999.

Huang, B., Hu, Z. Z., Kinter, J. L., Wu, Z., and Kumar, A.: Connection of stratospheric QBO with global atmospheric general circulation and tropical SST. Part 1: methodology and composite life cycle, Clim. Dynam., 38,, 1-23, 2012.

Jacobi, Ch., Kurschner, D., Muller, H. G., Pancheva, D., Mitchell, N. N., and Naujokat, B.: response of the mesopause region dynamics to the February 2001 stratospheric warming, J. Atmos. Terr. Phys., 65, 843-855, 2003.

Kleist, D. T., Parrish, D. F., Derber, J. C., Treadon, R., Wu, W. S., and Lord, S.: Introduction of the GSI into the NCEP Global Data Assimilation System, Wea. Forecasting, 24, 1691-1705, 2009.

Kumar, P. and Foufoula-Georgiou, E.: Wavelet analysis for geophysical applications, Rev. Geophys., 35, 385-412, 1997.

Kurihara, J., Ogawa, Y., Oyama, S., Nozawa, S., Tsutsumi, M., Hall, C. M., Yomikawa, Y., and Fujii, R.: Links between a stratospheric sudden warming and thermal structures and dynamics in the high-latitude mesosphere, lower thermosphere, and ionosphere, Geophys. Res. Lett., 37, L13806, doi:10.1029/2010GL043643, 2010

Labitzke, K.: Inter-annual variability of the winter stratosphere in the northern hemisphere, Mon. Weather Rev., 105, 762-770, 1977.

Labitzke, K.: On the interannual variability of the middle stratosphere during the northern winters, J. Meteorol. Soc. Jpn., 60, 124-139, 1982.

Labitzke, K. and Naujokat, B.: The lower Arctic stratosphere in winter since 1952, SPARC Newsl., 15, 11-14, 2000.

Lawrence, B. N., Fraser, G. J., Vincent, R., and Phillips, A.: The 4-day wave in the Antarctic mesopause, J. Geophys. Res., 100, 18899-18908, 1995.

Malinga, S. B. and Ruohoniemi, J. M.: The quasi-two-day wave studied using the Northern Hemisphere SuperDARN HF radars, Ann. Geophys., 25, 1767-1778, doi:10.5194/angeo-25-17672007, 2007.

Manney, G. L., Daffer, W. H., Strawbridge, K. B., Walker, K. A., Boone, C. D., Bernath, P. F., Kerzenmacher, T., Schwartz, M. J., Strong, K., Sica, R. J., Krüger, K., Pumphrey, H. C., Lambert, A., Santee, M. L., Livesey, N. J., Remsberg, E. E., Mlynczak, M. G., and Russell III, J. R.: The high Arctic in extreme winters: vortex, temperature, and MLS and ACE-FTS trace gas evolution, Atmos. Chem. Phys., 8, 505-522, doi:10.5194/acp-8-505-2008, 2008a.

Manney G. L., Kruger, K., Pawson, S., Minschwaner, K., Schwartz, M. J., Daffer, W. H., Livesey, N. J., Mlynczak, M. G., Remsberg, E. E., Russell III, J. M., and Waters, J. W.: The evolution of the stratopause during the 2006 major warming: Satellite data and assimilated meteorological analyses, J. Geophys. Res., 113,
D11115, doi:10.1029/2007JD009097, 2008b.

Manney, G. L., Schwartz, M. J., Kruger, K., Santee, M. L., Pawson, S., Lee, J. N., Daffer, W. H., Fuller, R. A., and Livesey, N. J.: Aura Microwave Limb Sounder observations of dynamics and transport during the record-breaking 2009 Arctic stratospheric major warming, Geophys. Res. Lett., 36, L12815, doi:10.1029/2009GL038586, 2009.

Manson, A. H. and Meek, C. E.: Climatologies of mean winds and tides observed by medium frequency radars at Tromso $(70 \mathrm{~N})$ and Sakatoon (52N) during 1987-1989, Can. J. Phys., 69, 966-975, 1991.

Matsuno, T.: A dynamical model of the stratospheric sudden warming, J. Atmos. Sci., 28, 1479-1494, 1971.

Mbatha, N., Sivakumar, V., Malinga, S. B., Bencherif, H., and Pillay, S. R.: Study on the impact of sudden stratosphere warming in the upper mesosphere-lower thermosphere regions using satellite and HF radar measurements, Atmos. Chem. Phys., 10, 3397 3404, doi:10.5194/acp-10-3397-2010, 2010.

Newman, P. A. and Nash, E. R.: The unusual Southern Hemisphere stratosphere winter of 2002, J. Atmos. Sci., 62, 614-628, 2004.

Pancheva, D. V.: Quasi-2-day wave and tidal variability observed over Ascension Island during January/February 2003, J. Atmos. Sol. Terr. Phys., 68, 390-403, 2006.

Pancheva, D., Mukhtarov, P., and Andonov, B.: Zonally symmetric oscillations in the Northern hemisphere stratosphere during the winter of 2003/2004, Geophys. Res. Lett., 34, L04807, doi:10.1029/2006GL028666, 2007.

Pancheva, D., Mukhtarov, P., Mitchell, N. J., Andonov, B., Merzlyakov, E., Singer, W., Murayama, Y., Kawamura, S., Xiong, J., Wan, W., Hocking, W., Fritts, D., Riggin, D., Meek, C., and Manson, A.: Latitudinal wave coupling of the stratosphere and mesosphere during the major stratospheric warming in 2003/2004, Ann. Geophys., 26, 467-483, doi:10.5194/angeo-26-467-2008, 2008.

Press, W. H., Teukolsky, S. A., Vetterling, W. T., and Flannery, B. P., Numerical Recipes in C: The Art of Scientific Computing, 2nd Edition, Cambridge University Press, Cambridge, 994 pp., 1992.

Quiroz, R. S.: The dominations of the amplitude and altitude of stratospheric warmings from satellite -measured radiance changes, J. Appl. Meteor., 10, 555-574, 1971.

Rienecker, M. M., Suarez, M. J., Todling, R., Bacmeister, J., Takacs, L., Liu, H.-C., Gu, W., Sienkiewicz, M., Koster, R. D., Gelaro, R., Stajner, I., and Nielsen, J. E.: Rhe GEOS-5 data assimilation system- documentation of versions 5.01, 5..0, and 5.2.0, Techinal report series on global modeling and data assimilation, Vol. 27, 92 pp., NASA/TM-2008-104606, 2008.

Rienecker, M. M., Suarez, M. J., Galero, R., Todling, R., Bacmeister, J., Liu, E., Bosilovich, G., Schubert, S. D., Takacs, L., Kim, G. K., Bloon, S., Chen, J., Collins, D., Conaty, A., Silva, A. D., Gu, W., Joiner, J., Koster, R. D., Lucchesi, R., Molod, A., Owens, T., Pawson, S., Pegion, P., Redder, C. R., Reichle, R., Robertson, F. R., Ruddick, A. G., Sienkiewicz, M., and Woolen, J.: MERRA: NASA's Modern-ERA Retrospective Analysis for research and Applications, J. Climate, 24, 3264-3468, 2011.

Scherhag, R.: Stratospheric temperature changes and the associated changes in pressure distribution, J. Meteorol., 17, 572-585, 1960.

Schwartz, M. J., Read, W. G., and Snyder, W. V.: Polarized radiative transfer for Zeeman-split oxygen lines in the EOS MLS forward model, IEEE Trans. GeoSci. Remote Sens., 44, 1182-1191, 
doi:10.1109/TGRS.2005.862267, 2006.

Scwartz, M. J., Lambert, A., Manney, G. L., Read, W. G., Livesey, N. J., Froidevaux, L., Ao, C. O., Bernath, P. F., Boone, C. D., Cofield, R. E., Daffer, W. H., Drouin, B. J., Fetzer, E. J., Fuller, R. A., Jamot, R. F., Jiang, J. H., Jiang, Y. B., Knosp, B. W., Kruger, K., Li, J.-L. F., Mlynczak, M. G., Pawson, S., Russell III, J. M., Santee, M. L., Snyder, W. V., Stek, P. C., Thurstans, R. P., Tompkins, A. M., Wagner, P. A., Walker, K. A., Waters, J. W., and Wu, W. L.: Validation of the Aura Microwave Limb Sounder temperature and geopotential height measurements, J. Geophys. Res., 113, D15811, doi:10.1029/2007JD008783, 2008.

Sinclair, S. and Pegram, G. G. S.: Empirical Mode Decomposition in 2-D space and time: a tool for space-time rainfall analysis and nowcasting, Hydrol. Earth Syst. Sci., 9, 127-137, doi:10.5194/hess-9-127-2005, 2005.

Singer, W., Hoffmann, P., Keuer, D., Scminder, R., and Kurschner, D.: Wind in the middle atmosphere with partial reflection measurements during winter and spring in middle Europe, Adv. Space Res., 12, 299-302, 1992.

Smith, A. K.: The origin of stationary planetary waves in the upper mesosphere, J. Atmos. Sci., 60, 3033-3041, 2003.

Thurairajah, B., Collins, R. L., Lynn Harvey, V., Lieberman, R. S., Gerding, M., Mizutani, K., and Livingston, J. M.: Gravity wave activity in the Arctic stratosphere and mesosphere during the 2007-2008 and 2008-2009 stratospheric warming events, J. Geophys. Res., 115, D00N06, doi:10.1029/2010JD014125, 2010 .
Venkat Ratnam, M., Tsuda, T., Jacobi, C., and Aoyama, Y: Enhancement of gravity wave activity observed during a major Southern Hemisphere stratospheric warming by CHAMP/GPS measurements, Geophys. Res. Lett., 31, L16101, doi:10.1029/2004GL019789, 2004.

Waters, J. E., Froidevaux, L., Harwood, R. S., Jarnot, R. F., Pickett, H. M., Read, W. G., Siegel, P. H., Cofield, R. E., Filipiak, M. J., Flower, D. A., Holden, J. R., Lau, G. K., Livesey, N. J., Manney, G. L., Pumphrey, H. C., Santee, M. L., Wu, D. L., Cuddy, D. T., Lay, R. R., Loo, M. S., Perun, V. S., Schwartz, M. J., Stek, P. C., Thurstans, R. P., Boyles, M. A., Chandra, K. M., Chavez, M. C., Chen, G.-S., Chudasama, B. V., Dodge, R., Fuller, R. A., Girard, M. A., Jiang, J. H., Jiang, Y., Knosp, B. W., LaBelle, R. C., Lam, J. C., Lee, K. A., Miller, D., Oswald, J. E., Patel, N. C., Pukala, D. M., Quintero, O., Scaff, D. M., Snyder, W. V., Tope, M. C., Wagner, P. A., and Walch, M. C.: The Earth Observing System Microwave Limb Sounder (EOS MLS) on the Aura Satellite, IEEE Trans. Geosci. Remote. Sens., 44, 1075-1092, 2006.

$\mathrm{Xu}$, Y., Liu, J., and Reimenschneider, S.: Two dimensional empirical mode decomposition by finite elements, Proceedings of the Royal Society A, 462, 2074, 3081-3096, 2006. 